\title{
A EMENDA DA REELEIÇÃo E A LEI DE RESPONSABILIDADE FISCAL: IMPACTOS SOBRE CICLOS POLÍTICOS E PERFORMANCE FISCAL DOS ESTADOS (1986-2002)*
}

\author{
Marcos Yamada Nakaguma ${ }^{\S}$ \\ Siegfried Bender
}

\begin{abstract}
RESUMO
O presente trabalho estuda o comportamento fiscal dos Estados brasileiros no período 1986-2002, analisando, em particular, o impacto de duas mudanças institucionais recentes, a Emenda da Reeleição e a Lei de Responsabilidade Fiscal, sobre os ciclos políticos orçamentários e sobre a performance fiscal dos Estados. Os resultados obtidos apontam que a Emenda da Reeleição implicou a intensificação dos ciclos políticos, estimulando manipulações oportunistas durante o período eleitoral; a Lei de Responsabilidade Fiscal, por sua vez, constituiu um instrumento efetivo para o controle do endividamento e para a redução das despesas de custeio dos Estados. Constatou-se também que a amplitude dos ciclos políticos tem diminuído ao longo do tempo, fato que poderia ser atribuído ao aprendizado do eleitorado e à experiência adquirida com eleições sucessivas, que contribuem para elevar o nível de controle político, reduzindo, assim, a intensidade dos ciclos.
\end{abstract}

Palavras-chave: ciclos políticos, controle eleitoral, reeleição, Lei de Responsabilidade Fiscal.

\begin{abstract}
This paper studies the fiscal behavior of Brazilian Federal States in the period 1986-2002, focusing, in particular, on the effects of two recent institutional changes, the "Reelection Amendment" and the "Fiscal Responsibility Law", on political budget cycles and on fiscal performance. The results provide evidence that the Reelection Amendment caused intensification in political cycles, stimulating opportunistic manipulations during the electoral period; and the Fiscal Responsibility Law constituted an effective instrument to control indebtedness and to reduce functionalism spending in States. The evidence also shows that the magnitude of the political cycles has been decreasing in time, a fact that could be attributed to the electorate's learning and experience in successive elections, which contribute to increase the level of political control, so reducing the intensity of the cycles.
\end{abstract}

Key words: political cycles, electoral control, electoral legislation, fiscal policy.

JEL classification: E62, H72.

\footnotetext{
* Os autores agradecem a Marcos José Mendes e a um parecerista anônimo por comentários e sugestões valiosas. Agradecem, ainda, ao CNPq pelo apoio financeiro concedido a esta pesquisa.

$\S \quad$ IPE-USP.marcosyn@yahoo.com.br.

○ FEA-USP.sieg@usp.br.

Endereço de contato: Av. Prof. Luciano Gualberto, 908, Cidade Universitária, São Paulo - SP, CEP: 05508-010.

Recebido em agosto de 2004. Aceito em setembro de 2005.
} 


\section{INTRODUÇÃO}

O presente artigo estuda o comportamento fiscal dos Estados brasileiros no período 19862002, analisando, em particular, o impacto de duas mudanças institucionais recentes, a "Emenda da Reeleição"1 e a Lei de Responsabilidade Fiscal, ${ }^{2}$ sobre os ciclos políticos orçamentários e sobre a performance fiscal dos Estados.

Um grande número de pesquisas recentes tem se dedicado ao estudo dos efeitos do calendário eleitoral sobre políticas e variáveis econômicas no Brasil. ${ }^{3}$ Como regra, esses trabalhos têm concluído que a orientação eleitoreira sobre as políticas é bastante forte. Neste sentido, é razoável supor que, ao alterar o sistema eleitoral vigente, a Emenda da Reeleição tenha modificado as formas com que os governantes conduzem as políticas públicas. Deste modo, o presente estudo analisa se a possibilidade de reeleição aumentou ou diminuiu os estímulos para a manipulação oportunista, isto é, se a magnitude dos ciclos políticos aumentou ou diminuiu com a Emenda da Reeleição.

A questão reside em se determinar qual entre duas forças contrárias tem prevalecido: se (1) o oportunismo eleitoral, que estimula o governante a adotar políticas expansionistas com o intuito de elevar a probabilidade de se reeleger, ou se (2) o controle político exercido pelo eleitorado, que restringe o uso discricionário e de finalidade meramente eleitoreira dos instrumentos políticos. A primeira tendência é enfatizada pelos modelos de ciclos eleitorais oportunísticos, enquanto a segunda é ressaltada pelos modelos de controle eleitoral.

Quanto à Lei de Responsabilidade Fiscal, este trabalho investiga quais os seus efeitos sobre as finanças públicas estaduais, avaliando a sua eficácia como instrumento de controle do endividamento e de melhoria da composição do financiamento e do gasto público.

As principais conclusões deste trabalho são as seguintes: (1) contrariamente aos resultados anteriormente obtidos, ${ }^{4}$ concluiu-se que a Emenda da Reeleição elevou as despesas e o endividamento dos Estados nos anos eleitorais; (2) a Lei de Responsabilidade Fiscal reduziu significativamente as despesas de custeio e as receitas de capital, além de ter elevado a receita corrente e tributária dos Estados, contribuindo, assim, para tornar o financiamento do gasto público mais sustentável no longo prazo; (3) a magnitude dos ciclos políticos tem diminuído ao longo do tempo.

Este estudo está dividido da seguinte maneira: na seção 2, procede-se à revisão da literatura relacionada aos modelos de ciclos políticos oportunísticos e de controle eleitoral; na seção 3, discute-se o modelo econométrico adotado e suas variáveis; na seção 4, apresentam-se as estimativas das regressões; por fim, na seção 5, conclui-se o trabalho, assinalando-se os seus principais resultados e conclusões.

\section{REVISÃO DA LITERATURA}

A Emenda da Reeleição, ao criar a possibilidade de um governante permanecer no cargo por um mandato adicional, internalizou os benefícios e os custos da manipulação eleitoreira das políticas públicas, alterando os incentivos para a adoção de estratégias oportunistas; de um lado,

\footnotetext{
Emenda Constitucional n 16 , de junho de 1997.

Lei Complementar $n^{\circ} 101$, de maio de 2000.

Fialho (1997) e Ogura (2002) investigaram a existência de ciclos políticos em variáveis macroeconômicas, como taxa de crescimento e inflação; Bonomo e Terra (1999) encontraram evidências de ciclos na taxa de câmbio real; Paiva (1994) constatou a existência de comportamento cíclico nos preços regulados; Bittencourt e Hillbrecht (2003) observaram ciclos na política fiscal dos Estados.

4 Ver Meneguin e Bugarin (2001).
} 
acentuando-os, pois, agora, os seus benefícios serão usufruídos pelo próprio político, e não pelo seu sucessor; e, de outro lado, reduzindo-os, pois a Reeleição forçou os governantes a levarem em conta os efeitos negativos futuros de suas políticas. Na literatura, os benefícios decorrentes da manipulação eleitoreira são enfatizados pelos modelos de ciclos políticos oportunísticos, enquanto que os seus custos são enfatizados pelos modelos de controle eleitoral, em particular, na formulação proposta por Meneguin e Bugarin (2001).

Os modelos de ciclos oportunísticos assumem que os políticos são motivados exclusivamente pela busca da própria eleição. ${ }^{5}$ Assim, para aumentar a probabilidade de serem reeleitos, os governantes possuiriam fortes incentivos para manipular as políticas públicas com o intuito de sinalizar sua competência para o eleitorado. ${ }^{6}$ De acordo com estes modelos, caso não houvesse a possibilidade de reeleição, não haveria motivo algum para a manipulação oportunista e, portanto, para a existência dos ciclos eleitorais. Assim, estes surgiriam somente quando a reeleição fosse permitida.

Rogoff e Silbert (1988) e Rogoff (1990) foram os primeiros a formular modelos de ciclos políticos orçamentários, nos quais os instrumentos da política fiscal são utilizados para sinalizar a competência do governante. Em Rogoff e Silbert (1988), a sinalização da competência ocorre por meio da diminuição de impostos no período pré-eleitoral, financiando-se o gasto público via senhoriagem ou de empréstimos menos visíveis; tal comportamento induziria um padrão cíclico de corte de impostos, antes das eleições, e de inflação e elevação da dívida, posteriormente a elas. Em Rogoff (1990), por sua vez, a sinalização é feita por meio de modificações na composição do orçamento, aumentando-se o gasto público em itens mais visíveis, como transferências, consumo e serviços, e diminuindo-se o gasto com investimentos, cujos resultados exigem mais tempo para serem percebidos pelo eleitorado.

Os modelos de controle eleitoral, por outro lado, enfatizam a idéia de que as eleições funcionam como instrumento disciplinador do comportamento dos governantes, pois é por meio delas que o eleitorado escolhe os políticos que julga estarem aptos para representá-lo no poder. É neste sentido que se pode afirmar que se, por um lado, as eleições estimulam os políticos a demonstrar competência, conforme ressaltam os modelos de ciclos políticos, por outro, as eleições, como instrumentos de controle, atuam no sentido de limitar a manipulação oportunista das políticas.

Os modelos desta linha teórica baseiam-se nos artigos precursores de Barro (1973) e Ferejohn (1986). Dentro desta tradição, Meneguin e Bugarin (2001) propuseram um modelo formalizando a idéia de que caso o governante não tenha possibilidade de se reeleger ele maximizará sua utilidade dentro do mandato, sem se preocupar com os efeitos futuros de sua política. Assim, nos casos em que não há reeleição, o benefício do déficit, do ponto de vista do político que está deixando o cargo, é elevado, porquanto será outra pessoa a encarregada de arcar com os serviços da dívida.

Desta forma, o instituto da reeleição, como argumentaram Meneguin e Bugarin, incentivaria os governantes a não se endividarem excessivamente, sendo que quanto maior a probabilidade de se reeleger, mais conservador será o governante em sua política fiscal. ${ }^{7}$ Tal resultado é particularmente interessante, por ser oposto às conclusões dos modelos de ciclos oportunísticos; enquanto Meneguin e Bugarin (2001) defendem o instituto da Reeleição como uma forma de contenção de gastos, aqueles modelos argumentam que os ciclos políticos se tornariam mais acentuados.

5 Ver Alesina et al. (1997), Drazen (2000, 2001) e Frazense (2002) para revisões da literatura sobre ciclos políticos.

6 Mais precisamente, deve-se ressaltar que os modelos de Rogoff e Silbert (1988) e Rogoff (1990) prevêem hipóteses em que não haveria incentivo algum para a distorção das políticas. Isso ocorreria no caso em que um governante incompetente estivesse no poder, dado que este, sendo incapaz de gerar ciclos similares ao de políticos competentes, preferiria manter a política fiscal socialmente ótima. Desta forma, a manipulação eleitoreira das políticas ocorrerá apenas quando um candidato competente estiver no poder, e ainda assim quando este perceber que a política socialmente ótima não é suficiente para sinalizar sua competência.

7 Neste sentido, Besley e Case (1995) encontraram evidências, para os estados americanos, de que governantes que podem se candidatar à reeleição são mais responsáveis do ponto de vista fiscal. 


\section{MODELO ECONOMÉTRICO}

Assumindo a perspectiva de que os incentivos introduzidos pela Reeleição atuam conjuntamente na determinação do comportamento observado das variáveis, o presente trabalho se propõe a testar qual dessas tendências tem prevalecido.

O estudo baseou-se em um modelo genérico, especificado da seguinte maneira:

$$
y_{i t}=\gamma \cdot y_{i, t-1}+D P_{i t}^{\prime} \cdot \beta+\theta_{1} \cdot E R_{i t}+\theta_{2} \cdot L R F_{i t}+\omega_{i t}^{\prime} \cdot \chi+a_{i}+\varepsilon_{i t} \text {, }
$$

em que $i=1, \ldots, 27$ representa um Estado e $t=1986, \ldots, 2002$ representa um ano entre 1986 e 2002. No modelo, $y_{i, t}$ representa o logaritmo da variável dependente; $D P_{i, t}$ é um conjunto de variáveis eleitorais, composto por três dummies: uma para o ano pré-eleitoral, outra para o ano eleitoral e uma última para o ano pós-eleitoral; $E R_{i, t}$ e $L R F_{i, t}$, representam as variáveis de interesse, Emenda da Reeleição e Lei de Responsabilidade Fiscal; $\omega_{i, t}$ é o conjunto de variáveis de controle utilizado; $a_{i}$ é o efeito específico não-observado de cada Estado e $\varepsilon_{i, t}$ é um erro iid.

\subsection{Descrição das variáveis}

O modelo básico proposto inclui defasagens da variável dependente. A inclusão dessas defasagens dentro do conjunto de variáveis explicativas gera viés nos estimadores de efeito-fixo (FE), na medida em que estes pressupõem a exogeneidade estrita das variáveis explicativas. ${ }^{8}$ Este viés será uma função de $T$, o número de períodos abrangidos pela amostra, e o estimador de FE será consistente apenas quando $T \rightarrow \infty$, o que não é o caso do presente estudo. Para contornar tal problema, foi considerado também o estimador do método generalizado dos momentos (GMM) proposto por Arellano e Bond (1991). Atendidas certas condições, este estimador será consistente quando aplicado a modelos de painel dinâmico.

O ciclo eleitoral é caracterizado por um conjunto de três dummies: uma para o ano pré-eleitoral (preelect), uma para o ano eleitoral (elect) e outra para o ano pós-eleitoral (postelect). Procurouse, com o uso destas dummies, especificar, de forma genérica e completa, o ciclo eleitoral em seu todo, e não somente nos anos eleitorais.

A variável ER busca captar os efeitos da Emenda da Reeleição sobre o ciclo eleitoral. Ela assume valor igual a 1 nas eleições em que, a partir de 1998, houve candidato concorrendo à reeleição. ${ }^{10}$ Ressalte-se que o pequeno número de observações disponíveis constitui um fator limitador para a análise. ${ }^{11}$ Além disto, observe-se que a maioria dos governantes que se candidataram novamente ao mesmo cargo foram reeleitos, fato que poderia, a princípio, sugerir que estes competem em condições privilegiadas. ${ }^{12}$

A variável LRF assume valor igual a 1 a partir do ano de 2000. Embora a Lei de Responsabilidade Fiscal tenha entrado em vigor somente em maio de 2000, há justificativas para incluir este ano na análise, pois, como explicam Nunes e Nunes (2003), “(...) ainda que se considere que, no pri-

8 Ver Wooldridge (2002, cap. 10).

9 Tais condições são as seguintes: (1) os instrumentos não podem estar correlacionados com os resíduos e (2) o erro, عi,t, não pode ser autocorrelacionado.

10 Ver apêndice A.

11 Ao todo, foram observadas apenas 25 ocorrências para ER.

12 Nas eleições de 1998, entre os candidatos que concorriam à reeleição, 65\% venceram (esta proporção é ainda mais elevada nos Estados da região Norte), enquanto apenas $40 \%$ dos governadores que não se candidataram à reeleição conseguiram eleger um sucessor do mesmo partido ou coligação. Nas eleições de 2002, entre os candidatos à reeleição, $75 \%$ venceram, enquanto apenas $37 \%$ dos políticos não candidatos conseguiram deixar sucessor . 
meiro ano, o ajuste fiscal foi parcial porque as administrações já trabalhavam com orçamentos aprovados no ano anterior, muitos ajustes que não dependiam dos orçamentos foram efetivamente realizados."

Deve-se ressaltar, porém, que as estimativas referentes à variável LRF devem ser interpretadas com muita cautela. A limitação é inerente à própria natureza do objeto deste estudo. A vigência da Lei de Responsabilidade Fiscal se estende por todo o território nacional, o que implica a inexistência de um grupo de controle. Diante disto, a alternativa mais imediatamente encontrada foi a de construir uma variável dummy que captasse todas as variações institucionais ocorridas no período 2000-2002, dentre as quais a de que a Lei de Responsabilidade Fiscal fosse responsável por uma parcela apenas. Assim, não é possível isolar com precisão o efeito da lei sobre a performance fiscal observada. O que se espera, porém, como um objetivo mais modesto, é que com os controles efetuados se possa captar o sinal correto do efeito induzido pela nova lei.

Para garantir a obtenção de estimativas não-viesadas para os efeitos de ER e LRF, foi necessário controlar por fatores que, potencialmente, exerceram influência sobre as variáveis fiscais estudadas. Primeiramente, para fazer o controle pela ocorrência de choques macroeconômicos durante o período de análise incluiu-se a taxa de variação do PIB nacional. Além disso, para captar o componente estrutural das contas orçamentárias ao longo do período, adicionou-se ao modelo uma tendência determinística - trend. Por fim, incluiu-se uma variável denominada trendpol para captar a tendência na variação da amplitude dos ciclos eleitorais ao longo do tempo. Esta variável assume valor igual a 1 para 1986, 2 para 1990, 3 para 1994, 4 para 1998, 5 para 2002 e zero para os demais anos nos quais não houve eleições. Testou-se, ainda, uma especificação não-linear, buscando captar uma evolução a taxas decrescentes para esta tendência. Os resultados, entretanto, não se alteraram de maneira significativa. ${ }^{13}$

A justificativa teórica para a inclusão da variável trendpol encontra-se no fato de o aprendizado do eleitorado e a experiência adquirida com eleições sucessivas contribuírem para elevar o nível de controle político, reduzindo, assim, a intensidade dos ciclos. Este argumento é enfatizado por Brender e Drazen (2004), que o utilizam para explicar o fato de a manipulação da política fiscal ser mais significativa em democracias mais jovens. Especificamente, estes autores encontraram evidências de que a amplitude do ciclo político orçamentário decresce à medida que eleições são realizadas, fato que explicaria, então, a diferença existente no comportamento do ciclo político entre democracias jovens e velhas. Um resultado análogo para as províncias russas foi obtido por Akhmedov e Zhuravskaya (2004). A expectativa, portanto, é de que as estimativas para a variável trendpol apresentem sinal negativo, indicando uma redução na amplitude do ciclo eleitoral ao longo do tempo.

Considerando que o escopo do presente trabalho é justamente analisar o efeito de uma mudança na legislação eleitoral sobre o ciclo político, a inclusão da variável trendpol no modelo é crucial. Se houver, de fato, uma tendência decrescente na amplitude dos ciclos, então desconsiderar a trendpol acarretaria um viés de omissão de variável, sobretudo porque a Emenda da Reeleição passou a exercer influência sobre o ciclo somente nos últimos anos da amostra. Neste caso, seria essencial incluir a trendpol no modelo para que se pudesse distinguir entre aquilo que é efeito da tendência daquilo que é efeito da Emenda da Reeleição. Assim, seria de se esperar que a não inclusão da trendpol implicasse estimativas para a Reeleição, que apontassem, erroneamente, que esta teve o efeito de reduzir a magnitude do ciclo político, já que se está ignorando a existência da tendência. Por outro lado, se não existir tendência decrescente no ciclo, isto é, se a variável trendpol for irrelevante, então a sua adição ao modelo acarretaria, apenas, estimativas menos precisas, o que, tendo em vista a discussão anterior, representa um custo bastante aceitável. ${ }^{14}$

13 Ver apêndice B.

14 Ver Greene (2002, cap. 8). Para uma discussão adicional, Ver apêndice B. 
Duas outras variáveis foram consideradas: uma variável de ideologia partidária, left ${ }^{15}$ e uma variável identificadora das eleições em que houve ocorrência de segundo turno. Como na maioria dos trabalhos realizados para o Brasil não se encontrou significância para a variável partidária, ${ }^{16}$ constatação compatível com a idéia de que os partidos políticos brasileiros não possuem orientações ideológicas claras e definidas. ${ }^{17}$ Além disto, as estimativas para a dummy de segundo turno se revelaram altamente insignificantes, sugerindo que esta variável não constitui um bom indicador de competição eleitoral. Desta forma, decidiu-se pela sua exclusão dos modelos.

\subsection{Dados}

As variáveis fiscais estudadas são apresentadas a seguir. Do lado da receita: (1) receita total: total de recursos auferidos, desdobrados nas categorias receitas de capital e receitas correntes; (2) receitas correntes: receitas que se esgotam dentro do período anual; compreendem as receitas tributárias, patrimoniais, industriais e outras de natureza semelhante, bem como as provenientes de transferências correntes; (3) receitas tributárias: composta pela arrecadação dos tributos da competência dos Estados mais transferências - faz parte da receita corrente; (4) receitas de capital: compreende a constituição de dívidas, a conversão em espécie de bens e direitos, reservas, bem como as transferências de capital; (5) operações de crédito: levantamento de empréstimos pelas entidades da administração pública, com o objetivo de financiar seus projetos e/ou atividades - compõe parcela das receitas de capital.

Do lado da despesa: (6) despesa total: total de despesas realizadas, composta por despesas correntes e por despesas de capital; (7) despesas correntes: despesas realizadas com a manutenção dos equipamentos e com o funcionamento dos órgãos públicos; (8) despesa de custeio: despesas necessárias à prestação de serviços e à manutenção da ação da administração - é componente da despesa corrente; (9) despesas de capital: despesas realizadas com o propósito de formar e/ou adquirir ativos reais, abrangendo, entre outras ações, o planejamento e a execução de obras, a compra de instalações, equipamentos, bem como a amortização de dívida e concessões de empréstimos.

Entre as despesas classificadas por funções, foram estudados os gastos com: (10) segurança pública; (11) educação e cultura; (12) saúde e saneamento; (13) assistência e previdência; e (14) transporte.

Considerou-se, ainda, a variável (15) receita orçamentária, definida como a diferença entre receita e despesa correntes.

Os dados relativos às variáveis fiscais foram obtidos na Secretaria do Tesouro Nacional ${ }^{18}$ do Ministério da Fazenda. Os dados utilizados na criação das variáveis políticas foram obtidos no Laboratório de Estudos Experimentais (LEEX) do Instituto Universitário de Pesquisas do Rio de Janeiro da Universidade do Rio de Janeiro. ${ }^{19}$ Todos os dados foram desinflacionados e ajustados para refletirem valores per capita.

15 Foram considerados partidos de esquerda: PDT, PTB, PRS, PSB e PT.

16 A única exceção se refere ao gasto com educação, que é consistentemente maior sob administrações de esquerda.

17 Neste sentido, Bittencourt e Hillbrecht (2003) citam a seguinte passagem de Kraemer (1997): "a ausência de um governo ideológico é uma aproximação realista para a América Latina, onde as estruturas partidárias são muito voláteis e a orientação ideológica dos políticos são nebulosas ou podem mudar rápida e radicalmente."

18 Site: http://www.stn.fazenda.gov.br

19 Site: http://www.iuperj.br/leex. 


\section{Resultados}

Os resultados para os estimadores de FE e de GMM foram reportados, embora os comentários estejam baseados, preponderantemente, neste último método, devido à sua propriedade de consistência. Apesar disso, deve-se ressaltar que os resultados obtidos por ambos os estimadores são qualitativamente compatíveis.

A consistência do estimador de GMM depende da validade dos instrumentos utilizados. Desta maneira, dois testes, sugeridos por Arellano e Bond (1991), foram aplicados. O primeiro, é o teste de Sargan, cuja hipótese nula é a de que os instrumentos sejam não correlacionados com os resíduos. O segundo, é um teste de autocorrelação no erro, cuja hipótese nula é a de não-correlação serial no nível de $\varepsilon i, t$. Adianta-se que, para todas as regressões, os testes de Sargan e de autocorrelação do termo aleatório atestaram a validade dos instrumentos.

A análise dos resultados foi dividida em quatro partes, de acordo com o tipo de classe fiscal a que pertence a variável dependente: em 4.1 analisam-se as variáveis relativas à receita orçamentária, em 4.2 as variáveis de despesa, em 4.3 o resultado orçamentário, e em 4.4 as despesas por função.

\subsection{Receitas}

Inicialmente, com o intuito de facilitar a compreensão das estimativas, interpreta-se, a título de ilustração, os resultados obtidos para a variável Receita Total. A regressão estimada por GMM resultou nos seguintes coeficientes estimados - com os p-valores dos testes reportados entre parênteses:

$$
\begin{aligned}
& \log (\text { rectot })=-0,022 \text { left }-0,005 \text { preelect }+0,285 \text { elect }-0,040 \text { postelect }+ \\
& (0,44) \quad(0,78) \quad(0,00) \quad(0,05) \\
& \text { 0,060ER - 0,090LRF + 0,007PIB - 0,079trendpol } \\
& (0,32) \quad(0,00) \quad(0,08) \quad(0,00)
\end{aligned}
$$

$$
\text { Sargan }=25,80 \quad \text { Serial Corr. }=0,960
$$

A especificação logarítmica para a variável dependente implica que os coeficientes estimados devam ser interpretados em termos porcentuais. Por exemplo, uma elevação de um ponto porcentual no PIB nacional acarreta um aumento de $0,7 \%$ na receita total.

Relativamente aos coeficientes das dummies preelect e postelect, tem-se que no ano pré-eleitoral, a receita total é $0,5 \%$ menor do que no ano-base (o segundo ano do mandato), enquanto que no ano pós-eleitoral a receita total é 4,0\% menor, embora apenas este último resultado seja estatisticamente significante. A variação da receita total em anos eleitorais, por sua vez, é obtida por meio da seguinte operação $-\beta e l e c t+\beta$ trendpol $\times$ trendpol - , refletindo o fato de que os ciclos nos anos eleitorais seguem uma determinada tendência. Assim, em 1986, ano em que trendpol =1, a receita total se elevou em 20,6\% (=28,5 - 7,9×1); em 1990, ano em que trendpol $=2$, a receita total se elevou em $12,7 \%$ (= 28,5 - 7,9×2), e assim por diante, evidenciando uma queda na magnitude dos ciclos ao longo do tempo. 
Tabela 1 - Variáveis de receita

\begin{tabular}{|c|c|c|c|c|c|c|c|c|c|c|}
\hline \multirow[b]{2}{*}{ Método } & \multicolumn{2}{|c|}{ Receita Total } & \multicolumn{2}{|c|}{ Receita Corrente } & \multicolumn{2}{|c|}{ Receita Tributária } & \multicolumn{2}{|c|}{ Receita de Capital } & \multicolumn{2}{|c|}{ Operações de Crédito } \\
\hline & $\mathrm{FE}$ & GMM & $\mathrm{FE}$ & GMM & FE & GMM & $\mathrm{FE}$ & GMM & FE & GMM \\
\hline \multirow[t]{2}{*}{$y(-1)$} & 0,442 *** & 0,484 *** & 0,590 *** & $0,529 * * *$ & 0,811 & 0,792 *** & 0,414 & $0,437^{* * *}$ & $0,13 * * *$ & $-0,03$ \\
\hline & {$[0,00]$} & {$[0,00]$} & {$[0,00]$} & {$[0,00]$} & {$[0,00]$} & {$[0,00]$} & {$[0,00]$} & {$[0,00]$} & {$[0,00]$} & {$[0,71]$} \\
\hline \multirow[t]{2}{*}{$y(-2)$} & $-0,003$ & 0,042 & $-0,171^{* * *}$ & $-0,191 * * *$ & $-0,136$ & $-0,147^{* *}$ & 0,063 & 0,120 & 0,05 & $-0,03$ \\
\hline & {$[0,93]$} & {$[0,14]$} & {$[0,00]$} & {$[0,00]$} & {$[0,00]$} & {$[0,03]$} & {$[0,18]$} & {$[0,11]$} & {$[0,03]$} & {$[0,47]$} \\
\hline \multirow[t]{2}{*}{ Left } & $-0,009$ & $-0,022$ & 0,008 & 0,186 & 0,003 & 0,003 & $-0,119$ & $-0,310$ & $-4,52$ * & $-8,18$ \\
\hline & {$[0,60]$} & {$[0,44]$} & {$[0,46]$} & {$[0,36]$} & {$[0,76]$} & {$[0,82]$} & {$[0,21]$} & {$[0,17]$} & {$[0,08]$} & {$[0,34]$} \\
\hline \multirow[t]{2}{*}{ Preelect } & $-0,005$ & $-0,005$ & 0,001 & 0,005 & $-0,030$ ** & $-0,020$ & $-0,192$ ** & $-0,325^{* *}$ & $-7,11^{* * *}$ & 0,51 \\
\hline & {$[0,74]$} & {$[0,78]$} & {$[0,95]$} & {$[0,64]$} & {$[0,01]$} & {$[0,12]$} & {$[0,01]$} & {$[0,03]$} & {$[0,00]$} & {$[0,95]$} \\
\hline \multirow[t]{2}{*}{ Elect } & 0,273 *** & $0,285^{* * *}$ & 0,183 *** & $0,157^{* * *}$ & $0,449 * * *$ & 0,448 *** & $-0,090$ & $-0,287$ & $-15,40 * * *$ & $-10,33$ \\
\hline & {$[0,00]$} & {$[0,00]$} & {$[0,00]$} & {$[0,00]$} & {$[0,00]$} & {$[0,00]$} & {$[0,63]$} & {$[0,31]$} & {$[0,00]$} & {$[0,40]$} \\
\hline \multirow[t]{2}{*}{ Postelect } & $-0,033^{* *}$ & $-0,040$ ** & 0,007 & 0,126 & 0,012 & 0,016 & $-0,584$ *** & $-0,565^{* * *}$ & $-13,90$ *** & $-24,31$ *** \\
\hline & {$[0,04]$} & {$[0,05]$} & {$[0,49]$} & {$[0,30]$} & {$[0,27]$} & {$[0,20]$} & {$[0,00]$} & {$[0,00]$} & {$[0,00]$} & {$[0,01]$} \\
\hline \multirow[t]{2}{*}{$E R$} & $0,084^{* * *}$ & 0,060 & 0,031 ** & 0,038 ** & 0,007 & 0,004 & 0,419 ** & 0,438 & 2,35 & 37,61 * \\
\hline & {$[0,00]$} & {$[0,32]$} & {$[0,04]$} & {$[0,04]$} & {$[0,66]$} & {$[0,85]$} & {$[0,02]$} & {$[0,27]$} & {$[0,62]$} & {$[0,09]$} \\
\hline \multirow[t]{2}{*}{$L R F$} & $-0,094^{* * *}$ & $-0,090^{* * *}$ & 0,030 ** & 0,039 * & $0,054^{* * *}$ & $0,068^{* * *}$ & $-0,972^{* * *}$ & $-0,551^{* *}$ & $-38,20^{* * *}$ & $-78,14^{* * *}$ \\
\hline & {$[0,00]$} & {$[0,00]$} & {$[0,02]$} & {$[0,06]$} & {$[0,00]$} & {$[0,00]$} & {$[0,00]$} & {$[0,03]$} & {$[0,00]$} & {$[0,00]$} \\
\hline \multirow[t]{2}{*}{$P I B$} & 0,003 & 0,007 * & 0,003 & 0,004 & $0,023^{* * *}$ & $0,025^{* * *}$ & 0,013 & 0,027 & $-0,92^{* * *}$ & $-1,33$ \\
\hline & {$[0,23]$} & {$[0,08]$} & {$[0,13]$} & {$[0,20]$} & {$[0,00]$} & {$[0,00]$} & {$[0,32]$} & {$[0,57]$} & {$[0,00]$} & {$[0,13]$} \\
\hline \multirow[t]{2}{*}{ Trend } & $0,039 * * *$ & -- & $0,029 * * *$ & -- & $0,015^{* * *}$ & -- & $0,072^{* * *}$ & -- & $2,93^{* * *}$ & -- \\
\hline & {$[0,00]$} & & {$[0,00]$} & & {$[0,00]$} & & {$[0,00]$} & & {$[0,00]$} & \\
\hline \multirow[t]{2}{*}{ TrendPol } & $-0,081^{* * *}$ & $-0,079$ *** & $-0,041^{* * *}$ & $-0,030$ *** & $-0,094^{* * *}$ & $-0,091^{* * *}$ & $-0,029$ & $-0,020$ & $1,97^{* *}$ & $-2,92$ \\
\hline & & {$[0,00]$} & {$[0,00]$} & {$[0,01]$} & {$[0,00]$} & {$[0,00]$} & {$[0,58]$} & {$[0,81]$} & {$[0,04]$} & {$[0,52]$} \\
\hline \multirow[t]{2}{*}{ Constant } & -- & $0,032^{* * *}$ & -- & $0,029 * * *$ & -- & 0,016 *** & -- & 0,030 & - & 5,83 *** \\
\hline & & {$[0,00]$} & & {$[0,00]$} & & {$[0,00]$} & & {$[0,27]$} & & {$[0,00]$} \\
\hline \multirow[t]{2}{*}{ Sargan } & -- & 25,80 & - & 25,56 & -- & 26,52 & -- & 21,42 & -- & 11,12 \\
\hline & & {$[1,00]$} & & {$[1,00]$} & & {$[1,00]$} & & {$[1,00]$} & & {$[1,00]$} \\
\hline \multirow[t]{2}{*}{ SerialCorrel. } & -- & 0,960 & - & 1,510 & -- & $-0,330$ & -- & $-0,820$ & -- & 0,820 \\
\hline & & {$[0,33]$} & & {$[0,13]$} & & {$[0,74]$} & & {$[0,41]$} & & {$[0,41]$} \\
\hline Obs. & 401 & 374 & 401 & 374 & 395 & 368 & 395 & 366 & 405 & 378 \\
\hline
\end{tabular}

Observações: As variáveis dependentes aparecem na forma logarítmica, exceção feita às operações de crédito, que apresentou grande número de observações com valor nulo. Os p-valores das estimativas estão reportados entre parênteses. ***, ${ }^{*} \mathrm{e}^{*}$ denotam significância ao nível de $1 \%, 5 \%$ e $10 \%$, respectivamente.

O coeficiente da variável ER indica a variação induzida na receita de um ano eleitoral decorrente do fato de existir candidato concorrendo à reeleição. As estimativas revelam que, nestes casos, a receita total deverá ser $6 \%$ maior, embora esta estimativa não seja estatisticamente significante. Quanto à variável LRF, os resultados indicam que a receita total reduziu-se 9,0\% em decorrência da Lei de Responsabilidade Fiscal.

Por fim, com relação aos testes de validade dos instrumentos, não se pôde rejeitar a hipótese de que os instrumentos sejam não-correlacionados com o erro (teste de Sargan), assim como não se pôde rejeitar a hipótese de inexistência de autocorrelação serial no termo aleatório (teste de correlação serial), de modo que os instrumentos podem ser considerados válidos. 
No geral, os resultados revelam a existência de ciclos políticos em todas as variáveis da receita orçamentária, embora nem todos apresentem o mesmo formato. Os ciclos nas receitas corrente e tributária se caracterizam por grandes elevações no ano eleitoral, retornando à média a partir do ano seguinte. Os ciclos nas receitas de capital e nas operações de crédito, por outro lado, apresentam fortes quedas no ano pós-eleitoral, evidenciando a ocorrência de ajustes fiscais que acompanham o calendário eleitoral e que se realizam nos períodos mais favoráveis do ponto de vista político.

O ciclo para a receita de capital se caracteriza por fortes diminuições nos anos pré- e póseleitorais, evidenciando a existência de ajustes fiscais cíclicos. No período pré-eleitoral, a receita de capital cai 32,5\%, e visa, provavelmente, criar condições para um aumento concentrado dos gastos durante as eleições. No período pós-eleitoral, ocorre um ajuste mais rigoroso, havendo uma diminuição de $56,5 \%$ na receita de capital, possibilitada pelo ambiente político favorável que costuma seguir às eleições. Bittencourt e Hillbrecht (2003) encontraram resultados diferentes. Segundo estes autores, o pico das receitas de capital ocorreria no ano pré-eleitoral, fato que atribuem à necessidade de garantir recursos um ano antes das eleições.

Com relação ao ciclo nas operações de crédito, constata-se uma redução significativa de seu valor, cerca de $\mathrm{R} \$ 24$ per capita, nos anos pós-eleitorais, refletindo, da mesma forma, a ocorrência de ajustes fiscais nestes períodos. ${ }^{20}$

Note-se que o aumento das receitas corrente e tributária durante o ano eleitoral sugere aparente contradição com as predições de Rogoff e Silbert (1988). Segundo estes autores, o financiamento do gasto público em anos eleitorais é alterado com a elevação dos empréstimos e com a diminuição dos tributos. ${ }^{21} \mathrm{~A}$ este respeito, entretanto, cabe a ressalva de que a principal fonte de receita tributária dos Estados é o ICMS, imposto sobre a circulação de bens e serviços. ${ }^{22}$ Assim, deve-se esperar que nos anos eleitorais a arrecadação tributária se eleve endogenamente, impulsionada pelo aumento das transações na economia, induzida pelo ciclo político dos Estados e do governo federal. ${ }^{23}$ A hipótese de elevação das alíquotas, por outro lado, parece pouco plausível, pois depende de aprovação legislativa, processo altamente desgastante, principalmente em períodos próximos às eleições. Portanto, os resultados encontrados para as receitas corrente e tributária não devem ser considerados contrários à teoria.

Com relação à variável ER, os resultados mostram que a possibilidade de reeleição ampliou os ciclos eleitorais nas variáveis de receita orçamentária, indicando que candidatos à reeleição têm maior incentivo para distorcer a arrecadação, de modo a, possivelmente, criar condições para a elevação dos gastos. De acordo com as estimativas, a ER implicou uma elevação das receitas correntes em 3,8\% e em aumento, embora não significante, de $6 \%$ nas receitas totais. ${ }^{24}$ Uma explicação para a elevação das receitas correntes poderia ser atribuída à maior arrecadação tributária dos Estados em que ocorrem candidaturas à reeleição, ainda que a estimativa de ER na regressão para a receita tributária não tenha sido estatisticamente significante. De fato, como se mostrará adiante, a constatação de que a despesa corrente dos Estados se eleva quando há candidatura à reeleição fornece bases para esta hipótese, considerando, como se argumentou, que as despesas elevam endogenamente a arrecadação tributária.

20 Como se verá adiante, o comportamento do ciclo nas receitas de capital e nas operações de crédito é bastante semelhante ao comportamento do ciclo nas despesas de capital, o que, possivelmente, reflete o fato de que as despesas de capital são, em sua maioria, financiadas por empréstimos.

21 A maioria dos trabalhos empíricos tem obtido resultados favoráveis a esta hipótese, e.g., Shi e Svensson (2002) e Persson e Tabellini (2003).

22 Segundo Nunes e Nunes (2003), em 2001 a arrecadação do ICMS foi responsável por 55\% do total das receitas orçamentárias estaduais.

23 As eleições nas esferas estadual e federal ocorrem simultaneamente.

24 A estimativa por FE, porém, se mostrou significante. 
Além disso, pode-se observar que a ER elevou significativamente o montante das operações de crédito realizadas: aproximadamente $\mathrm{R} \$ 37$ per capita. O coeficiente de ER para a variável receita de capital, porém, não foi significante na estimativa por GMM, embora o seu sinal positivo seja compatível com a idéia de que candidatos à reeleição possuem maiores incentivos para se endividarem. ${ }^{25}$

Quanto à LRF, apesar de ter acarretado uma redução de $9 \%$ na receita total, ela induziu a uma melhoria na composição das receitas dos Estados, criando condições para um financiamento mais sustentável do gasto público. A LRF implicou elevação das receitas corrente e tributária em, respectivamente, $3,9 \%$ e $6,8 \%$, e acarretou, por outro lado, uma diminuição significativa das receitas de capital, em 55,1\%, e das operações de crédito, em $\mathrm{R} \$ 78$ per capita.

O aumento das receitas corrente e tributária pode ser atribuído ao fato de que a LRF introduziu, no processo orçamentário, regras que dificultaram a renúncia de receitas, impondo, também, a instituição, previsão e efetiva arrecadação de todos os tributos da competência constitucional dos Estados. Acrescente-se, ainda, que os limites estabelecidos para o endividamento público devem ter implicado, ainda que indiretamente, elevação da eficiência tributária e elevação da alíquota de alguns impostos.

Quanto às receitas de capital e às operações de crédito, a LRF impôs limites para o estoque de dívida consolidada, definindo regras para que os Estados se ajustassem a este limite por meio de superávits primários. Além disso, restringiu-se o fluxo de endividamento, impondo-se um limite máximo de $16 \%$ da receita líquida corrente (RLC) para as operações de crédito, de forma a evitar que um governo, embora ajustado, pudesse evoluir rapidamente para uma situação de endividamento excessivo.

Por fim, constatou-se que a trendpol entrou significativamente nas regressões para as receitas total, corrente e tributária. O mesmo não ocorreu nas regressões para a receita de capital e para as operações de crédito, uma vez que estas variáveis não apresentam ciclos com auge nos anos eleitorais, como as demais. Desta forma, os resultados obtidos evidenciam que a magnitude dos ciclos políticos tem diminuído consistentemente ao longo do tempo, corroborando a idéia de que o eleitorado, adquirindo experiência democrática, aprende a identificar o oportunismo eleitoral e passa a puni-lo.

\subsection{Despesas}

Os ciclos políticos nas variáveis da despesa orçamentária, da mesma forma que ocorre no lado das receitas, são bastante nítidos, indicando que o padrão do gasto público é fortemente influenciado por considerações eleitoreiras. As evidências obtidas revelam que os políticos distorcem todos os tipos de despesa de modo a concentrá-las nos períodos próximos às eleições, nos quais se espera que os retornos eleitorais sejam maiores.

Os ciclos nas despesas total, corrente e de custeio apresentam elevações significativas nos anos eleitorais, aumentando cerca de 42,9\%, 46,2\% e 27\%, respectivamente. No período pós-eleitoral, por sua vez, a despesa total se reduz, situando-se cerca de 3,7\% abaixo do nível do ano-base, enquanto que a despesa de custeio permanece 6,7\% acima da média, talvez devido à rigidez legal que impossibilite uma diminuição mais rápida dos gastos nesta variável.

25 A estimativa por FE, porém, se mostrou significante. 
Tabela 2 - Variáveis de despesa

\begin{tabular}{|c|c|c|c|c|c|c|c|c|}
\hline \multirow[b]{2}{*}{ Método } & \multicolumn{2}{|c|}{ Despesa Total } & \multicolumn{2}{|c|}{ Despesa Corrente } & \multicolumn{2}{|c|}{ Despesa de Custeio } & \multicolumn{2}{|c|}{ Despesa de Capital } \\
\hline & $\mathrm{FE}$ & GMM & $\mathrm{FE}$ & GMM & $\mathrm{FE}$ & GMM & $\mathrm{FE}$ & GMM \\
\hline \multirow[t]{2}{*}{$y(-1)$} & $0,446^{* * *}$ & $0,509 * * *$ & $0,510^{* * *}$ & $0,569 * * *$ & $0,646^{* * *}$ & $0,659^{* * *}$ & $0,353^{* * *}$ & $0,358^{* * *}$ \\
\hline & {$[0,00]$} & {$[0,00]$} & {$[0,00]$} & {$[0,00]$} & {$[0,00]$} & {$[0,00]$} & {$[0,00]$} & {$[0,00]$} \\
\hline \multirow[t]{2}{*}{$y(-2)$} & 0,076 ** & $0,098^{* * *}$ & 0,018 & $-0,025$ & $-0,041$ & $-0,046$ & 0,091 ** & $0,201^{* * *}$ \\
\hline & {$[0,05]$} & {$[0,00]$} & {$[0,67]$} & {$[0,68]$} & {$[0,37]$} & {$[0,26]$} & {$[0,04]$} & {$[0,00]$} \\
\hline \multirow[t]{2}{*}{ Left } & $-0,020$ & $-0,026$ & $-0,012$ & $-0,001$ & $-0,020$ & $-0,028$ & $-0,055$ & $-0,039$ \\
\hline & {$[0,15]$} & {$[0,37]$} & {$[0,33]$} & {$[0,96]$} & {$[0,48]$} & {$[0,38]$} & {$[0,25]$} & {$[0,58]$} \\
\hline \multirow[t]{2}{*}{ Preelect } & $-0,011$ & 0,003 & $-0,010$ & 0,003 & $-0,015$ & $-0,020$ & $-0,016$ & 0,029 \\
\hline & {$[0,43]$} & {$[0,88]$} & {$[0,41]$} & {$[0,86]$} & {$[0,50]$} & {$[0,49]$} & {$[0,71]$} & {$[0,67]$} \\
\hline \multirow[t]{2}{*}{ Elect } & $0,443^{* * *}$ & $0,429^{* * *}$ & 0,447 *** & $0,462 * * *$ & $0,252^{* * *}$ & $0,270^{* * *}$ & $0,292^{* *}$ & 0,272 \\
\hline & {$[0,00]$} & {$[0,00]$} & {$[0,00]$} & {$[0,00]$} & {$[0,00]$} & {$[0,00]$} & {$[0,01]$} & {$[0,12]$} \\
\hline \multirow[t]{2}{*}{ Postelect } & $-0,045^{* * *}$ & $-0,037$ & 0,015 & 0,027 & 0,060 ** & $0,067^{* * *}$ & $-0,335^{* * *}$ & $-0,293 * * *$ \\
\hline & {$[0,01]$} & {$[0,11]$} & {$[0,36]$} & {$[0,14]$} & {$[0,03]$} & {$[0,01]$} & {$[0,00]$} & {$[0,00]$} \\
\hline \multirow[t]{2}{*}{$E R$} & 0,046 & 0,047 & 0,032 * & 0,062 * & 0,032 & 0,052 & 0,161 & 0,153 \\
\hline & {$[0,16]$} & {$[0,47]$} & {$[0,10]$} & {$[0,10]$} & {$[0,33]$} & {$[0,22]$} & {$[0,12]$} & {$[0,36]$} \\
\hline \multirow[t]{2}{*}{$L R F$} & $-0,112^{* * *}$ & $-0,084^{* *}$ & $-0,047^{* * *}$ & $-0,017$ & $-0,201^{* * *}$ & $-0,204^{* * *}$ & $-0,213^{* * *}$ & $-0,239$ ** \\
\hline & {$[0,00]$} & {$[0,02]$} & {$[0,00]$} & {$[0,51]$} & {$[0,00]$} & {$[0,00]$} & {$[0,00]$} & {$[0,04]$} \\
\hline \multirow[t]{2}{*}{$P I B$} & $0,008^{* * *}$ & $0,012^{* * *}$ & $0,013^{* * *}$ & $0,014^{* * *}$ & $0,016^{* * *}$ & $0,017^{* * *}$ & $-0,005$ & 0,001 \\
\hline & {$[0,00]$} & {$[0,00]$} & {$[0,00]$} & {$[0,00]$} & {$[0,00]$} & {$[0,00]$} & {$[0,45]$} & {$[0,88]$} \\
\hline \multirow[t]{2}{*}{ Trend } & $0,033^{* * *}$ & -- & $0,031^{* * *}$ & -- & $0,032^{* * *}$ & -- & $0,026^{* * *}$ & -- \\
\hline & {$[0,00]$} & & {$[0,00]$} & & {$[0,00]$} & & {$[0,00]$} & \\
\hline \multirow[t]{2}{*}{ TrendPol } & $-0,099 * * *$ & $-0,093$ *** & $-0,103^{* * *}$ & $-0,104^{* * *}$ & $-0,039$ ** & $-0,045^{* * *}$ & $-0,063^{* *}$ & $-0,050$ \\
\hline & {$[0,00]$} & {$[0,00]$} & {$[0,00]$} & {$[0,00]$} & {$[0,03]$} & {$[0,01]$} & {$[0,05]$} & {$[0,25]$} \\
\hline \multirow[t]{2}{*}{ Constant } & -- & $0,024^{* * *}$ & -- & 0,026 *** & -- & $0,031^{* * *}$ & & 0,020 ** \\
\hline & & {$[0,00]$} & & {$[0,00]$} & & {$[0,00]$} & & {$[0,04]$} \\
\hline \multirow[t]{2}{*}{ Sargan } & - & 25,76 & - & 25,69 & -- & 26,06 & -- & 18,20 \\
\hline & & {$[1,00]$} & & {$[1,00]$} & & {$[1,00]$} & & {$[1,00]$} \\
\hline \multirow[t]{2}{*}{ SerialCorrel. } & -- & $-0,160$ & -- & $-0,260$ & - & 0,680 & -- & $-1,590$ \\
\hline & & {$[0,86]$} & & {$[0,79]$} & & {$[0,49]$} & & {$[0,11]$} \\
\hline Obs. & 401 & 374 & 401 & 374 & 401 & 374 & 401 & 374 \\
\hline
\end{tabular}

Observações: Todas as variáveis dependentes aparecem na forma logarítmica. Os p-valores das estimativas são reportados nos parênteses. ${ }^{* * *},{ }^{* *} \mathrm{e} *$ denotam significância ao nível de $1 \%, 5 \%$ e $10 \%$, respectivamente.

Com relação à despesa de capital, note-se que a evidência de ciclos políticos com auge no ano eleitoral sugere aparente contradição com as predições de Rogoff (1990). De acordo com o autor, haveria incentivos para que o governante, em um ano de eleições, modificasse a composição das despesas orçamentárias, reduzindo o investimento e elevando a despesa em áreas nas quais a percepção pelo eleitorado fosse mais imediata. Ressalte-se que esta conclusão está baseada no pressuposto teórico de que o investimento demora um período (um ano) para produzir seus efeitos, enquanto que o gasto com bens e serviços produz resultados imediatos. Esta premissa, entretanto, não pode ser aplicada, como regra, ao caso das eleições brasileiras, pois estas se realizam próximas ao final 
do ano, havendo, assim, tempo hábil para que uma obra iniciada no começo do ano seja finalizada antes das eleições. De fato, os resultados obtidos revelam que isto ocorre na prática. ${ }^{26}$

Ainda em relação à despesa de capital, observa-se, no ano pós-eleitoral, uma notável redução neste item de dispêndio, cerca de $29,3 \%$, indicando que o ajuste fiscal posterior às eleições se realiza, no lado das despesas, por meio de uma drástica redução nos gastos com investimento. Além disso, este resultado fornece indícios de que os “ajustes fiscais em geral”, isto é, aqueles que ocorrem independentemente de relação com o ciclo político, são realizados por meio da redução da despesa de capital, já que os gastos correntes e, em especial, a despesa de custeio, parecem ser mais rígidos.

Os resultados relativos aos impactos da ER sobre o gasto público revelam que a possibilidade de reeleição aumentou a despesa corrente em cerca de 6,2\%. Os coeficientes de ER para as demais variáveis não se mostraram estatisticamente significantes, embora o sinal positivo comum a todas elas esteja em conformidade com a idéia de que a reeleição aumentou os incentivos para a elevação do gasto. ${ }^{27}$

Estes resultados parecem demonstrativos do fato de que o dilema, enfrentado pelos políticos, entre o oportunismo eleitoral e o controle dos gastos se resolveu em favor do primeiro, corroborando as proposições da teoria dos ciclos políticos. De forma geral, os governantes parecem valorizar mais a sua permanência no cargo, pouco se importando com as conseqüências futuras de uma elevação do endividamento, de modo que a Emenda da Reeleição acabou ampliando a magnitude do ciclo político.

As constatações obtidas parecem fazer bastante sentido, principalmente quando se consideram as características das instituições políticas brasileiras e o longo histórico de refinanciamento das dívidas estaduais - "inconsistências dinâmicas" - por parte do governo federal. Este aspecto político parece contribuir para que as restrições orçamentárias futuras não sejam levadas em conta, ao menos da forma que seria socialmente desejável, pelo governante, quando este toma as suas decisões.

Quanto aos efeitos da LRF sobre o gasto público, as estimativas revelam que a lei contribuiu de forma decisiva para reduzir a generalidade das despesas governamentais. A LRF apresentou importante efeito sobre as despesas totais, que reduziram $8,4 \%$, e sobre as despesas de capital, que diminuíram 23,9\%. O essencial, porém, é notar que o principal objetivo da lei no que se refere ao gasto público, isto é, o controle dos gastos com pessoal, foi alcançado de forma expressiva, o que se constata pelo fato de que as despesas de custeio tiveram uma redução de cerca de $20,4 \%$.

A LRF estabeleceu um limite máximo para as despesas com pessoal, o componente principal das despesas de custeio. Para os Estados, os gastos com pessoal não poderiam ultrapassar $60 \%$ da receita corrente líquida (RCL), e os ajustes para atingir esta meta deveriam ser realizados obedecendo-se as seguintes regras: (1) regra permanente - para os Estados que estavam ajustados no momento em que a LRF entrou em vigência, os desajustes futuros deveriam ser reduzidos em dois quadrimestres; (2) regra transitória - para os Estados que estavam desajustados, estipulou-se o prazo de dois anos, isto é, até o final de 2002, para que estes reduzissem o excedente. Desta forma, a redução estimada de 20,4\% nas despesas de custeio reflete a necessidade de redução dos gastos com pessoal enfrentada pelos Estados em face dos limites impostos pela LRF.

26 Uma exceção, como se verá, se refere aos gastos com saúde e saneamento.

27 As estimativas por FE para as despesas de capital se mostraram marginalmente significantes $(\mathrm{p}$-valor $=0,12)$ e apontaram uma elevação de $16,1 \%$ em decorrência da reeleição.

28 Rocha e Giuberti (2004), analisando diretamente as séries para a despesa com pessoal, encontraram efeito no mesmo sentido. 
No que se refere à redução estimada das despesas de capital, uma explicação plausível poderia ser atribuída ao fato de que os limites impostos, pela lei, para o estoque da dívida e para as operações de crédito devam ter dificultado o acesso aos recursos necessários para os gastos com investimento. Uma razão adicional poderia ser identificada, na linha do que se argumentou acima, no fato de que, possivelmente, o ajuste fiscal imposto pela LRF recaiu, pelo menos no curto prazo, mais intensamente sobre as despesas de capital.

O PIB nacional entrou significativamente nas regressões das despesas total, corrente e de custeio: uma elevação do PIB em $1 \%$ aumenta em, aproximadamente, 1,5\% os gastos dessas variáveis. O desempenho do produto, porém, parece não afetar as despesas de capital, cujas decisões parecem seguir considerações de cunho político.

A variável trendpol também entrou de forma significante nas regressões, revelando uma tendência decrescente na amplitude dos ciclos nas variáveis do gasto público ao longo do tempo.

\subsection{Resultado orçamentário}

Tabela 3 - Variável resultado orçamentário

\begin{tabular}{|c|c|c|}
\hline \multirow[b]{2}{*}{ Método } & \multicolumn{2}{|c|}{ Resultado Orçamentário } \\
\hline & $\mathrm{FE}$ & GMM \\
\hline \multirow[t]{2}{*}{$\overline{y(-1)}$} & 0,06 & $0,17^{* \star *}$ \\
\hline & {$[0,23]$} & {$[0,01]$} \\
\hline \multirow[t]{2}{*}{$y(-2)$} & 0,00 & 0,02 \\
\hline & {$[0,97]$} & {$[0,79]$} \\
\hline \multirow[t]{2}{*}{ Left } & $-0,278$ & $-3,630$ \\
\hline & {$[0,96]$} & {$[0,72]$} \\
\hline \multirow[t]{2}{*}{ Preelect } & $-0,28$ & 3,27 \\
\hline & {$[0,93]$} & {$[0,69]$} \\
\hline \multirow[t]{2}{*}{ Elect } & $-49,98 * * *$ & $-93,83^{* * *}$ \\
\hline & {$[0,00]$} & {$[0,01]$} \\
\hline \multirow[t]{2}{*}{ Postelect } & $-15,44^{* * *}$ & $-13,75^{* *}$ \\
\hline & {$[0,00]$} & {$[0,05]$} \\
\hline \multirow[t]{2}{*}{$E R$} & $16,83^{\text {** }}$ & $-2,15$ \\
\hline & {$[0,02]$} & {$[0,92]$} \\
\hline \multirow[t]{2}{*}{$L R F$} & $-0,57$ & 0,15 \\
\hline & {$[0,91]$} & {$[0,98]$} \\
\hline \multirow[t]{2}{*}{$P I B$} & $-0,20$ & $-2,36$ * \\
\hline & {$[0,73]$} & {$[0,06]$} \\
\hline \multirow[t]{2}{*}{ Trend } & $1,69^{* * *}$ & - \\
\hline & {$[0,00]$} & \\
\hline \multirow[t]{2}{*}{ TrendPol } & 3,52 & 13,17 \\
\hline & {$[0,21]$} & {$[0,25]$} \\
\hline \multirow[t]{2}{*}{ Constant } & - & 3,09 ** \\
\hline & & {$[0,02]$} \\
\hline \multirow[t]{2}{*}{ Sargan } & -- & 14,05 \\
\hline & & {$[1,00]$} \\
\hline \multirow[t]{2}{*}{ SerialCorrel. } & -- & $-1,040$ \\
\hline & & {$[0,29]$} \\
\hline Obs. & 405 & 378 \\
\hline
\end{tabular}

Observações: Os valores para a variável dependente estão em reais. Os p-valores das estimativas são reportados nos parênteses. ${ }^{* *},{ }^{*} \mathrm{e}^{*}$ denotam significância ao nível de $1 \%, 5 \%$ e $10 \%$, respectivamente. 
As estimativas também demonstram a existência de ciclos eleitorais na variável de resultado orçamentário. ${ }^{29}$ As motivações eleitoreiras parecem constituir fator determinante para a deterioração das finanças estaduais durante os anos eleitorais, com a elevação dos déficits orçamentários em cerca de $\mathrm{R} \$ 93$ per capita.

A Emenda da Reeleição, por sua vez, não influenciou significativamente o resultado orçamentário. Tal constatação se deve ao fato de que, como anteriormente observado, a Reeleição induziu um aumento tanto nas despesas quanto nas receitas correntes, resultando em que o déficit final dos Estados, definido como a diferença entre essas duas variáveis, não foi afetado pela Emenda da Reeleição.

Também com relação à LRF, as estimativas não se revelaram estatisticamente significantes. Apesar de ter influenciado de forma positiva a composição dos gastos e das receitas públicas, a Lei de Responsabilidade Fiscal parece não ter apresentado impacto, ao menos no curto prazo, sobre o resultado orçamentário. A este respeito, vale mencionar que Nunes e Nunes (2003), comparando a evolução dos resultados nominais entre os anos de 2000 e 2001, constataram a ocorrência de uma ligeira piora na situação fiscal dos Estados. ${ }^{30}$ A explicação, segundo estes autores, residiria no fato de que as dívidas realizadas antes da lei afetam os resultados nominais posteriores, já que estes levam em conta os pagamentos de amortização e dos juros da dívida. A análise dos resultados primários, por outro lado, revelou uma melhoria da situação, evidenciando um esforço fiscal dos Estados no sentido de realizarem o ajuste.

Os resultados indicam que uma elevação de $1 \%$ no PIB induz a um crescimento no déficit de aproximadamente $\mathrm{R} \$ 2,36$, contrariando as implicações dos modelos de tax-smoothing, de acordo com os quais os déficits governamentais seriam utilizados de maneira contracíclica, de forma a garantir um nível de gastos do governo relativamente constante ao longo do tempo. A variável tren$d p o l$, por sua vez, não entrou significativamente nas regressões, embora o seu sinal positivo indique uma tendência de declínio na amplitude dos ciclos no resultado orçamentário.

\subsection{Despesa por função}

A análise dos componentes do gasto público revelou, no que se refere à forma e à intensidade do ciclo eleitoral, um comportamento distinto para as despesas de cada setor. Estes resultados corroboram a idéia de que os eleitores valorizam distintamente os investimentos em cada área, e que, conscientes deste fato, os políticos atuam oportunamente, concentrando os gastos nos setores mais "rentáveis" em termos de votos.

Os resultados obtidos por GMM para os gastos com segurança pública, diferentemente do que se poderia esperar, não evidenciaram a existência de ciclos políticos, embora as estimativas por FE apontem o contrário. Note-se que Bittencourt e Hillbrecht (2003) encontraram fortes evidências de ciclos nesta variável.

Os gastos com educação e, particularmente, os gastos com transporte ${ }^{31}$ apresentam expressivo ciclo político, com o dispêndio nestas categorias largamente concentrado em anos eleitorais; os gastos com educação se elevam $51,8 \%$ e os gastos com transporte são mais que duplicados durante as eleições. ${ }^{32}$ Adicionalmente, os resultados apontaram a existência de significativo ciclo partidário no

29 Este trabalho utiliza a seguinte definição: resultado orçamentário = receitas correntes - despesas correntes.

30 O conceito de resultado nominal corresponde à diferença entre receitas e despesas sem qualquer dedução.

31 O modelo de regressão para a variável transporte contém uma única defasagem, pois os testes rejeitaram a validade dos instrumentos na regressão com duas defasagens.

32 No mesmo sentido, Khemani (2001) encontrou evidências, para a Índia, de intensa elevação na kilometragem de estradas construídas em anos eleitorais. 
dispêndio com educação, demonstrando que os partidos de esquerda priorizam investimentos nesta área, e gastam, em média, 17,1\% a mais do que os partidos de centro e de direita. ${ }^{33}$

Tabela 4 - Variáveis de despesa por função

\begin{tabular}{|c|c|c|c|c|c|c|c|c|c|c|}
\hline \multirow[b]{2}{*}{ Método } & \multicolumn{2}{|c|}{ Segurança Pública } & \multicolumn{2}{|c|}{ Educação } & \multicolumn{2}{|c|}{ Saúde e Saneamento } & \multicolumn{2}{|c|}{ Assistência e Previdência } & \multicolumn{2}{|c|}{ Transporte } \\
\hline & FE & GMM & FE & GMM & FE & GMM & $\mathrm{FE}$ & GMM & FE & GMM \\
\hline \multirow[t]{2}{*}{$y(-1)$} & $0,494 * * *$ & 0,425 *** & $0,405^{* * *}$ & $0,435^{* * *}$ & 0,493 *** & 0,426 *** & $0,616^{* * *}$ & 0,428 *** & $0,409 * * *$ & $0,405^{* * *}$ \\
\hline & {$[0,00]$} & {$[0,00]$} & {$[0,00]$} & {$[0,00]$} & {$[0,00]$} & {$[0,00]$} & {$[0,00]$} & {$[0,00]$} & {$[0,00]$} & {$[0,00]$} \\
\hline \multirow[t]{2}{*}{$y(-2)$} & $-0,034$ & $-0,129$ & 0,082 * & 0,062 & $-0,001$ & 0,007 & $-0,022$ & $-0,075$ & -- & -- \\
\hline & {$[0,51]$} & {$[0,29]$} & {$[0,08]$} & {$[0,34]$} & {$[0,97]$} & {$[0,91]$} & {$[0,64]$} & {$[0,15]$} & & \\
\hline \multirow[t]{2}{*}{ Left } & 0,018 & $-0,019$ & 0,076 *** & $0,171^{* * *}$ & 0,014 & $-0,001$ & 0,032 & $-0,039$ & $-0,082$ ** & 0,078 \\
\hline & {$[0,11]$} & {$[0,69]$} & {$[0,00]$} & {$[0,01]$} & {$[0,68]$} & {$[0,98]$} & {$[0,23]$} & {$[0,68]$} & {$[0,02]$} & {$[0,30]$} \\
\hline \multirow[t]{2}{*}{ Preelect } & 0,008 & 0,044 & $-0,010$ & $-0,022$ & 0,073 * & 0,102 * & 0,079 *** & $0,168^{* * *}$ & $-0,020$ & 0,022 \\
\hline & {$[0,55]$} & {$[0,47]$} & {$[0,55]$} & {$[0,55]$} & {$[0,06]$} & {$[0,08]$} & {$[0,00]$} & {$[0,03]$} & {$[0,63]$} & {$[0,76]$} \\
\hline \multirow[t]{2}{*}{ Elect } & $0,252^{* * *}$ & 0,093 & 0,430 *** & 0,518 *** & 0,055 & $-0,034$ & 0,346 *** & $0,235^{*}$ & 1,010 *** & $1,130^{* * *}$ \\
\hline & {$[0,00]$} & {$[0,58]$} & {$[0,00]$} & {$[0,00]$} & {$[0,56]$} & {$[0,76]$} & {$[0,00]$} & {$[0,07]$} & {$[0,00]$} & {$[0,00]$} \\
\hline \multirow[t]{2}{*}{ Postelect } & 0,031 ** & 0,090 & 0,001 & 0,021 & $-0,025$ & 0,002 & $0,055^{* *}$ & 0,075 & $-0,230$ *** & $-0,148$ \\
\hline & {$[0,03]$} & {$[0,15]$} & {$[0,96]$} & {$[0,53]$} & {$[0,48]$} & {$[0,95]$} & {$[0,05]$} & {$[0,31]$} & {$[0,00]$} & {$[0,24]$} \\
\hline \multirow[t]{2}{*}{$E R$} & 0,024 & 0,039 & 0,058 * & 0,067 & $-0,024$ & $-0,128$ & $-0,067$ & $-0,184$ * & $0,229 * * *$ & 0,104 \\
\hline & {$[0,27]$} & {$[0,72]$} & {$[0,10]$} & {$[0,32]$} & {$[0,65]$} & {$[0,14]$} & {$[0,13]$} & {$[0,10]$} & {$[0,00]$} & {$[0,64]$} \\
\hline \multirow[t]{2}{*}{$L R F$} & 0,068 *** & 0,135 & $-0,049$ ** & $-0,039$ & $0,127^{* * *}$ & $0,221 * * *$ & $-0,260$ *** & $-0,391^{* * *}$ & 0,091 * & 0,366 * \\
\hline & {$[0,00]$} & {$[0,28]$} & {$[0,05]$} & {$[0,26]$} & {$[0,01]$} & {$[0,00]$} & {$[0,00]$} & {$[0,00]$} & {$[0,10]$} & {$[0,10]$} \\
\hline \multirow[t]{2}{*}{$P I B$} & 0,001 & $-0,002$ & $0,005^{*}$ & 0,006 & 0,008 & 0,004 & $0,010^{* *}$ & $-0,007$ & 0,010 * & 0,007 \\
\hline & {$[0,62]$} & {$[0,81]$} & {$[0,09]$} & {$[0,12]$} & {$[0,14]$} & {$[0,62]$} & {$[0,02]$} & {$[0,52]$} & {$[0,09]$} & {$[0,55]$} \\
\hline \multirow[t]{2}{*}{ Trend } & $0,031^{* * *}$ & -- & $0,033^{* * *}$ & -- & 0,002 & - & $0,044^{* * *}$ & -- & $-0,010$ ** & -- \\
\hline & {$[0,00]$} & & {$[0,00]$} & & {$[0,61]$} & & {$[0,00]$} & & {$[0,04]$} & \\
\hline \multirow[t]{2}{*}{ TrendPol } & $-0,050$ *** & 0,017 & $-0,106$ *** & $-0,124$ *** & 0,010 & 0,053 & $-0,052^{* *}$ & $-0,013$ & $-0,247^{* * *}$ & $-0,248$ *** \\
\hline & {$[0,00]$} & {$[0,76]$} & {$[0,00]$} & {$[0,00]$} & {$[0,56]$} & {$[0,14]$} & {$[0,02]$} & {$[0,73]$} & {$[0,00]$} & {$[0,00]$} \\
\hline \multirow[t]{2}{*}{ Constant } & -- & $0,025^{\text {*** }}$ & -- & $0,031^{* * *}$ & -- & $-0,003$ & -- & 0,062 *** & -- & $-0,027^{* *}$ \\
\hline & & {$[0,00]$} & & {$[0,00]$} & & {$[0,64]$} & & {$[0,00]$} & & {$[0,05]$} \\
\hline \multirow[t]{2}{*}{ Sargan } & -- & 22,73 & -- & 22,76 & -- & 14,42 & -- & 24,61 & -- & 20,76 \\
\hline & & {$[1,00]$} & & {$[1,00]$} & & {$[1,00]$} & & {$[1,00]$} & & {$[1,00]$} \\
\hline \multirow[t]{2}{*}{ SerialCorrel. } & -- & 0,350 & -- & $-0,400$ & -- & 0,010 & -- & $-0,720$ & -- & $-0,500$ \\
\hline & & {$[0,72]$} & & {$[0,68]$} & & {$[0,99]$} & & {$[0,46]$} & & {$[0,61]$} \\
\hline Obs. & 399 & 372 & 401 & 374 & 401 & 374 & 398 & 370 & 419 & 389 \\
\hline
\end{tabular}

Observações: Todas as variáveis dependentes aparecem na forma logarítmica. Os p-valores das estimativas são reportados nos parênteses. ${ }^{* *},{ }^{* *} \mathrm{e}^{*}$ denotam significância ao nível de $1 \%, 5 \%$ e $10 \%$, respectivamente.

Com relação às despesas com transporte, deve-se observar que os gastos neste setor se reduzem fortemente, cerca de 33,3\%, após o período eleitoral. Esta constatação se deve, provavelmente, à necessidade de realizar ajustes fiscais cíclicos após as eleições. Tal comportamento, note-se, é semelhante ao apresentado pelas despesas de capital, a conta orçamentária em que está alocada a maior parcela dos dispêndios com transporte. 
Os gastos com assistência e previdência também acompanham o ciclo político, com as despesas neste setor se elevando cerca de 23,5\% nos anos eleitorais. As estimativas evidenciam, ainda, que os gastos nesta área são bastante rígidos, sendo difícil elevá-los ou diminuí-los de um ano para o outro, resultado que é percebido pelo fato de os coeficientes das estimativas por FE para os anos pré- e pós-eleitorais serem significativamente maiores do que zero.

Os resultados para os gastos com saúde e saneamento evidenciaram a existência de ciclo político, mas este, diferentemente do que ocorre nas demais variáveis, possui seu auge no ano préeleitoral, aumentando 10,2\% em relação aos demais anos. Sob o prisma das teorias de ciclos orçamentários, este comportamento poderia ser atribuído ao fato de os investimentos em saneamento e saúde demandarem maior lapso de tempo para serem concluídos e, assim, para que o eleitorado possa usufruir seus benefícios. Portanto, tais investimentos devem ter seu início antecipado em relação aos demais.

A diferenciação entre investimentos mais ou menos visíveis ainda explica o fato da Emenda da reeleição ter implicado uma redução nos gastos com assistência e previdência em cerca de 18,4\%, já que investimentos neste setor apresentam, aparentemente, um apelo menos direto sobre o eleitorado. Constataram-se também indícios, ainda que não estatisticamente significantes, de que a Reeleição induziu a uma diminuição nos gastos com saúde e saneamento e, por outro lado, acarretou uma elevação nas despesas com educação e transporte. ${ }^{34}$ Neste sentido, os resultados indicam que os governantes candidatos à reeleição possuiriam incentivos ainda maiores para distorcerem o gasto público, direcionando-os para áreas em que os seus efeitos sejam mais explicitamente percebidos pelo eleitorado. ${ }^{35}$

A LRF, por sua vez, implicou um aumento nas despesas com saúde e saneamento e, por outro lado, diminuiu as despesas com assistência e previdência. Entretanto, deve-se ressaltar que as estimativas, neste ponto, devem ser bastante imprecisas, dada a grande quantidade de mudanças legislativas ocorridas durante o período, referentes, em particular, ao regime de funcionalismo público e ao sistema de previdência social. No tocante ao sistema de saúde, houve, em setembro de 2000, a aprovação da Emenda Constitucional 29, cujo objetivo principal foi o de assegurar recursos mínimos para financiar os serviços públicos de saúde. De qualquer forma, a LRF contribuiu para reduzir os dispêndios com assistência e previdência ao impor limites para os gastos com pessoal, que incluem as despesas com inativos e pensionistas. A LRF, por outro lado, estabeleceu normas para a gestão fiscal eficaz e transparente, limitando também o uso discricionário dos recursos públicos, fato que, possivelmente, deve ter se refletido na melhoria da qualidade do dispêndio público.

A variável PIB parece não ter influência definida e significativa na dinâmica dos investimentos públicos por setor. Por outro lado, os resultados para a trendpol apontaram uma tendência de decréscimo na amplitude dos ciclos em educação e transporte. O mesmo não foi constatado nas demais variáveis. ${ }^{36}$ A explicação para isso poderia ser atribuída ao fato de que: (1) o auge dos ciclos nos gastos com saúde ocorre no ano pré-eleitoral; (2) os gastos com segurança não apresentam um ciclo nítido e definido; e (3) os ciclos nos gastos com assistência e previdência são diferentes do usual, devido à rigidez constatada neste tipo de gasto.

34 Note-se que os coeficientes estimados por FE para as variáveis educação e transporte apresentaram sinal positivo e estatisticamente significante.

35 Uma explicação alternativa foi apresentada por Drazen e Eslava (2004), que formularam um modelo segundo com o qual o governante sinalizaria as suas preferências (e não a sua competência, diferentemente dos modelos de Rogoff, 1990 e Rogoff e Silbert, 1988) para os eleitores por meio de mudanças na composição do gasto público, adequando-a, o máximo possível, aos interesses do eleitorado. A estratégia seria a de manipular a política fiscal de modo a atrair grupos de eleitores que valorizam determinados tipos de gastos.

36 Embora as estimativas por FE para os gastos com segurança e com assistência e previdência apontem uma diminuição, estatisticamente significante, da magnitude dos ciclos. 


\section{CoNCluSÃo}

O presente trabalho buscou analisar o impacto da Emenda da Reeleição e da Lei de Responsabilidade Fiscal sobre os ciclos políticos orçamentários e sobre a performance fiscal dos Estados brasileiros. Os resultados obtidos apontam que (1) a Emenda da Reeleição implicou elevação dos ciclos políticos, estimulando manipulações oportunistas durante o período eleitoral; (2) a Lei de Responsabilidade Fiscal se constituiu em um instrumento efetivo para o controle do endividamento e para a redução das despesas de custeio dos Estados; e (3) que a amplitude dos ciclos políticos tem diminuído ao longo do tempo. A seguir, discutem-se as principais conclusões deste trabalho.

As evidências empíricas indicam que a Emenda da Reeleição elevou o incentivo para a manipulação eleitoreira das políticas públicas, evidenciando que o oportunismo eleitoral tem prevalência sobre o controle do eleitorado. Desta maneira, os resultados obtidos corroboram a teoria dos ciclos políticos em detrimento da teoria do controle eleitoral, em particular, na formulação proposta por Meneguin e Bugarin (2001).

Constatou-se, ainda, que do lado das receitas a Emenda da Reeleição elevou a arrecadação corrente, assim como o valor das operações de crédito, evidenciando haver uma maior predisposição para o endividamento por parte dos candidatos à reeleição. Do lado das despesas, observou-se que a Emenda da Reeleição implicou elevação do gasto corrente. Entre as despesas por função, a Emenda da Reeleição estimulou os governantes a direcionarem os gastos, nos anos eleitorais, para os setores mais visíveis, como educação e transporte, diminuindo, em contrapartida, o dispêndio com saúde e saneamento, e assistência e previdência.

A Lei de Responsabilidade Fiscal, por sua vez, constituiu um marco institucional importante para as finanças públicas nacionais, contribuindo para o controle do endividamento e para a melhoria da qualidade do gasto público.

Do lado das receitas, a Lei de Responsabilidade Fiscal implicou redução das receitas de capital e das operações de crédito, elevando, por outro lado, a arrecadação tributária. Desta maneira, contribuiu para que o financiamento dos Estados seja feito de maneira mais sustentável no longo prazo. Entre as despesas, os resultados indicaram que a Lei de Responsabilidade Fiscal diminuiu as despesas de custeio, em razão dos limites impostos para o gasto com pessoal, e as despesas de capital, em decorrência da limitação dos fluxos de empréstimo para os Estados.

As diferenças partidárias não influem de maneira relevante no comportamento fiscal dos Estados. A única exceção diz respeito aos gastos com educação, que é significativamente maior sob administrações de esquerda.

Por fim, a amplitude dos ciclos políticos tem diminuído ao longo do tempo, fato que pode ser atribuído ao amadurecimento do eleitorado, que, com a experiência que vai adquirindo ao longo de eleições sucessivas, passa a ser capaz de identificar e punir políticos oportunistas, reduzindo, assim, a intensidade dos ciclos.

\section{REFERÊNCIAS BIBLIOGRÁFICAS}

Akhmedov, A.; Zhuravskaya, E. Opportunistic political cycles: test in young democracy setting. Quarterly Journal of Economics, Ver 119, n. 4, p. 1301-1338, 2004.

Alesina, A.; Roubini, N.; Cohen, G. Political cycles and the macroeconomy. Cambridge, Massachussets: The MIT Press, 1997. 
Arellano, M.; Bond, S. Some tests of specification for panel data: Monte Carlo evidence and an application to employment equations. Review of Economic Studies, 58, p. 277-297, 1991.

Barro, R. The control of politicians: an economic model. Public Choice, 14, p. 19-42, 1973.

Besley, T.; Case, A. Does political accountability affect economic policy choices? Evidence from gubernatorial term limits. Quarterly Journal of Economics 110, p. 769-798, 1995.

Bittencourt, J. L.; Hillbrecht, R. Ciclo político na economia brasileira: um teste para a execução orçamentária dos governos estaduais - 1983/2000. Anais do XXXI Encontro Nacional de Economia. Porto Seguro: Anpec, dezembro 2003.

Bonomo, M.; Terra, C. The political economy of exchange rate policy in Brazil: 1964-1997. Ensaios Econômicos da EPGE-FGV, n. 341, 1999.

Brender, A.; Drazen, A. Political budget cycles in new versus established democracies. NBER Working Paper 10539, 2004.

Drazen, A. Political economy in macroeconomics. Princeton, NJ: Princeton University Press, 2000.

. The political business cycle after 25 years. Nat. Bur. Econ. Res. Macroecon Annu. 2000, 2001.

Drazen, A.; Eslava, M. Political budget cycles without deficits. University of Maryland, 2004. Mimeografado.

Ferejohn, J. Incumbent performance and electoral control. Public Choice, 50, p. 5-26, 1986.

Fialho, T. M. M. Testando a evidência de ciclos políticos no Brasil. Revista Brasileira de Economia, Ver 51, n. 3, p. 379-89, 1997.

Frazense, R. J. Electoral and partisan cycles in economic policies and outcomes. Annu. Rev. Polit. Sci, 5, X, 2002.

Greene, W. Econometric analysis. $5^{\mathrm{a}}$ ed. NJ: Upper Saddle River, Prentice Hall, 2002.

Khemani, S. Political cycles in a developing economy: effect of elections in the Indian States. The World Bank, Development Research Group, 2001. Mimeografado.

Kraemer, M. Electoral budget cycles in Latin America and Caribbean: incidence, causes and political futility. Working Paper Series, n. ${ }^{\circ}$ 354. Office of the Chief Economist, BID, 1997.

Meneguin, F. B.; Bugarin, M. S. Reeleição e política fiscal: um estudo dos efeitos nos gastos públicos. Economia Aplicada, Ver 5, n. 3, p. 600-22, jul./set. 2001.

Nunes, S.; Nunes, C. Dois anos da Lei de Responsabilidade Fiscal do Brasil: uma avaliação dos resultados à luz do modelo do fundo comum. Working Paper University of Brasília, n² 276, 2003.

Ogura, L. M. Political business cycles in Brazilian economy (1980-1999). Working Paper University of Brasilia, 2002.

Paiva, C. A. C. Interesses eleitorais e flutuações de preços em mercados regulados. Revista de Economia Política, 56, p. 31-41, 1994.

Rocha, F.; Giuberti, A. C. Consenso político com relação à necessidade de disciplina fiscal dos estados: um estudo da Lei de Responsabilidade Fiscal. Monografia agraciada com o segundo lugar no IX Prêmio de Monografia do Tesouro Nacional 2004, Tema Especial: Lei de Responsabilidade Fiscal, 2004.

Rogoff, K. Equilibrium political budget cycles. American Economic Review, 80, p. 21-26, 1990.

Rogoff, K.; Silbert, A. Elections and macroeconomic policy cycles. Review of Economic Studies. v. 55, n. 1, p. 1-16, 1988.

Shi, M.; Svensson, J. Political business cycles in developed and developing countries. Working Paper, The World Bank, February 2000. . Conditional political budget cycles. CEPR Discussion Paper, $N .^{\circ}$ 3352, 2002.

Wooldridge, J. Econometric analysis of cross section and panel data. Cambridge, MA: MIT Press, 2002. 


\section{APÊNDICE A}

A tabela a seguir mostra os valores atribuídos à dummy ER. Esta variável assume valor igual a 1 nas eleições em que houve governador candidato à reeleição, e zero, caso contrário; para as eleições anteriores a 1998 ela assume valor zero sempre, dado que até então os políticos não tinham a possibilidade de se reelegerem.

\section{Tabela 5 - Variável ER}

\begin{tabular}{lcc}
\hline Estado & 1998 & 2002 \\
\hline Acre & 0 & 1 \\
Alagoas & 0 & 1 \\
Amapá & 1 & 0 \\
Amazonas & 1 & 0 \\
Bahia & 0 & 0 \\
Ceará & 1 & 0 \\
Distrito Federal & 1 & 1 \\
Espírito Santo & 0 & 0 \\
Goiás & 0 & 1 \\
Maranhão & 1 & 0 \\
Mato Grosso & 1 & 0 \\
Mato Grosso do Sul & 0 & 1 \\
Minas Gerais & 1 & 0 \\
Pará & 1 & 0 \\
Paraíba & 0 & 0 \\
Paraná & 1 & 0 \\
Pernambuco & 1 & 1 \\
Piauí & 1 & 0 \\
Rio de Janeiro & 0 & 0 \\
Rio Grande do Norte & 0 & 0 \\
Rio Grande do Sul & 1 & 0 \\
Rondônia & 1 & 1 \\
Roraima & 1 & 0 \\
Santa Catarina & 1 & 1 \\
São Paulo & 1 & 0 \\
Sergipe & 1 & \\
Tocantins & 0 & 1 \\
\hline
\end{tabular}

\section{APÊNDICE B}

Este apêndice fornece uma discussão complementar a respeito da variável trendpol. Ele estende os resultados anteriormente obtidos em dois sentidos. Primeiro, para contornar a relativa rigidez imposta pela linearidade na evolução dos ciclos, considera-se uma especificação não-linear alternativa, buscando captar uma diminuição na amplitude dos ciclos a taxas decrescentes. O objetivo é verificar se os resultados até aqui obtidos são robustos a diferentes especificações para esta tendência. Para tanto, foi construída uma nova variável, denominada trendpol2, que assume os valores: 1 
para $1986,1+\log (2)$ para $1990,1+\log (3)$ para $1994,1+\log (4)$ para $1998,1+\log (5)$ para 2002 e zero para os demais anos. Em segundo lugar, são apresentadas as estimativas das regressões anteriores sem a variável trendpol. O objetivo é aferir se, e em que direção, a omissão desta variável afeta as estimativas.

A análise se restringirá à receita e à despesa orçamentária e, para simplificar a compreensão dos resultados, serão apresentadas somente as estimativas para as variáveis de interesse, ER e LRF. Além disso, apenas as regressões estimadas por GMM são reportadas.

Tabela 6 - Tendência no ciclo político: variáveis de receita

\begin{tabular}{|c|c|c|c|c|c|c|c|c|c|c|}
\hline & \multicolumn{2}{|c|}{ Receita Total } & \multicolumn{2}{|c|}{ Receita Corrente } & \multicolumn{2}{|c|}{ Receita Tributária } & \multicolumn{2}{|c|}{ Receita de Capital } & \multicolumn{2}{|c|}{ Operações de Crédito } \\
\hline & (1) & (2) & (1) & (2) & (1) & (2) & (1) & (2) & (1) & (2) \\
\hline \multirow[t]{2}{*}{$E R$} & 0,076 & $-0,022$ & 0,046 ** & 0,007 & 0,017 & $-0,071^{* * *}$ & 0,517 & 0,420 & 38,59 * & 34,64 * \\
\hline & {$[0,21]$} & {$[0,66]$} & {$[0,01]$} & {$[0,71]$} & {$[0,50]$} & {$[0,00]$} & {$[0,20]$} & {$[0,23]$} & {$[0,08]$} & {$[0,06]$} \\
\hline \multirow[t]{2}{*}{$L R F$} & $-0,097^{* * *}$ & $-0,111^{* * *}$ & $0,037^{*}$ & 0,030 & $0,061^{\text {*** }}$ & $0,034^{* * *}$ & $-0,541^{* *}$ & $-0,559$ ** & $-78,50^{* * *}$ & $-78,91^{* * *}$ \\
\hline & {$[0,00]$} & {$[0,00]$} & {$[0,08]$} & {$[0,15]$} & {$[0,00]$} & {$[0,06]$} & {$[0,04]$} & {$[0,03]$} & {$[0,00]$} & {$[0,00]$} \\
\hline \multirow[t]{2}{*}{ Trendpol2 } & $-0,302^{* * *}$ & -- & $-0,134^{* * *}$ & -- & $-0,337^{* * *}$ & -- & $-0,276$ & -- & $-12,32$ & -- \\
\hline & {$[0,00]$} & & {$[0,00]$} & & {$[0,00]$} & & {$[0,35]$} & & {$[0,43]$} & \\
\hline No Trendpol & & $\mathrm{x}$ & & $\mathrm{x}$ & & $x$ & & $\mathrm{x}$ & & $\mathrm{x}$ \\
\hline
\end{tabular}

Observações: Todas as variáveis dependentes aparecem na forma logarítmica. Os p-valores das estimativas são reportados nos parênteses. ${ }^{* *},{ }^{* *} \mathrm{e}{ }^{*}$ denotam significância ao nível de $1 \%, 5 \%$ e $10 \%$, respectivamente.

Tabela 7 - Tendência no ciclo político: variáveis de despesa

\begin{tabular}{|c|c|c|c|c|c|c|c|c|}
\hline & \multicolumn{2}{|c|}{ Despesa Total } & \multicolumn{2}{|c|}{ Despesa Corrente } & \multicolumn{2}{|c|}{ Despesa de Custeio } & \multicolumn{2}{|c|}{ Despesa de Capital } \\
\hline & (1) & (2) & (1) & (2) & $(1)$ & (2) & $(1)$ & (2) \\
\hline \multirow[t]{2}{*}{$E R$} & 0,588 & $-0,049$ & $0,075^{* *}$ & $-0,034$ & 0,080 * & 0,001 & 0,151 & 0,088 \\
\hline & {$[0,37]$} & {$[0,42]$} & {$[0,05]$} & {$[0,36]$} & {$[0,06]$} & {$[0,96]$} & {$[0,37]$} & {$[0,55]$} \\
\hline \multirow[t]{2}{*}{$L R F$} & $-0,093$ *** & $-0,111$ *** & $-0,026$ & $-0,053^{* *}$ & $-0,208$ *** & $-0,213^{* * *}$ & $-0,246^{* *}$ & $-0,256$ ** \\
\hline & {$[0,01]$} & {$[0,00]$} & {$[0,31]$} & {$[0,03]$} & {$[0,00]$} & {$[0,00]$} & {$[0,03]$} & {$[0,02]$} \\
\hline \multirow[t]{2}{*}{ Trendpol2 } & $-0,331$ *** & -- & $-0,374^{* * *}$ & -- & $-0,227^{* * *}$ & -- & $-0,151$ & -- \\
\hline & {$[0,00]$} & & {$[0,00]$} & & {$[0,00]$} & & {$[0,33]$} & \\
\hline No Trendpol & & $x$ & & $x$ & & $x$ & & $x$ \\
\hline
\end{tabular}

Observações: Todas as variáveis dependentes aparecem na forma logarítmica. Os p-valores das estimativas são reportados nos parênteses. ${ }^{* *},{ }^{* *} \mathrm{e}{ }^{*}$ denotam significância ao nível de $1 \%, 5 \%$ e $10 \%$, respectivamente.

As regressões estimadas com a variável trendpol2 geraram resultados bastante similares aos anteriores. Em termos gerais, as evidências continuam indicando que a Emenda da Reeleição ampliou a magnitude dos ciclos políticos, com a elevação das receitas e das despesas em anos eleitorais, e que a Lei de Responsabilidade Fiscal contribuiu para melhorar a composição das receitas e reduzir as despesas orçamentárias. É importante ressaltar também que os coeficientes estimados para a variável ER ficaram consistentemente acima das estimativas anteriormente obtidas, o que indica ciclos de maior intensidade. Deve-se notar, ainda, que a variável trendpol2 se mostrou altamente significante, exceção feita às regressões para a receita de capital, para as operações de crédito e para a despesa de capital, em resultado análogo aos anteriormente obtidos. A conclusão, portanto, é a 
de que os resultados apresentados neste trabalho são robustos a diferentes especificações para a trendpol.

A omissão da variável trendpol, por outro lado, alterou os resultados para a variável ER, o que se deu de forma bastante expressiva. Os coeficientes estimados ficaram consistentemente abaixo das estimativas anteriormente obtidas. Tal resultado se deve, como se argumentou, ao viés acarretado pela omissão da trendpol, que faz com que a variável ER passe a captar um efeito que, na verdade, não é seu, mas que advém da tendência de declínio dos ciclos eleitorais. Ainda assim, os resultados estimados não provêem suporte para a hipótese de que a Emenda da Reeleição atenuou os ciclos eleitorais, pois, em sua generalidade, os coeficientes estimados para ER se mostraram altamente insignificantes.

Do lado das receitas, as estimativas de ER para as receitas corrente e de capital, bem como para as operações de crédito, preservaram um sinal positivo, ainda que estatisticamente insignificante no caso das duas primeiras variáveis. Por outro lado, os coeficientes de ER para as receitas total e tributária inverteram de sinal, passando a negativo, embora somente as estimativas para esta última variável sejam significantes. Do lado das despesas, o sinal dos coeficientes se inverteu para as variáveis de despesa total e corrente, embora isto tenha ocorrido sem significância estatística. $\mathrm{O}$ coeficiente para as despesas de capital permaneceu com o sinal positivo, consistentemente com as conclusões anteriores.

Por fim, os resultados relativos à variável LRF permaneceram qualitativamente idênticos e permitem induzir às mesmas conclusões anteriormente assinaladas. 